\title{
UPPER AND LOWER SOLUTIONS FOR THE SINGULAR $p$-LAPLACIAN WITH SIGN CHANGING NONLINEARITIES VIA INEQUALITY THEORY ${ }^{1}$
}

\author{
HAISHEN LÜ \\ Department of Applied Mathematics, Hohai University, Nanjing, 210098, China, \\ e-mail: Haishen2001@yahoo.com.cn \\ DONAL O'REGAN \\ Department of Mathematics, National University of Ireland, Galway, Ireland \\ e-mail:donal.regan@nunigalway.ie
}

and RAVI P. AGARWAL

Department of Mathematical Sciences, Florida Institute of Technology, Melbourne, FL 32901-6975, USA e-mail: agarwal@fit.edu

(Received 8 June, 2004; accepted 20 May, 2005)

Abstract. In this paper, general existence theorems are presented for the singular
equation
\[ \left\{\begin{array}{l}-\left(\varphi_{p}\left(u^{\prime}\right)\right)^{\prime}=f\left(t, u, u^{\prime}\right), 0<t<1 \\ u(0)=u(1)=0 .\end{array}\right. \]
Throughout, our nonlinearity is allowed to change sign. The singularity may occur at
$u=0, t=0$ and $t=1$.

2000 Mathematics Subject Classification. 34B15, 34B16.

1. Introduction. In this paper, we study the singular boundary value problem

$$
\left\{\begin{array}{l}
-\left(\varphi_{p}\left(u^{\prime}\right)\right)^{\prime}=f\left(t, u, u^{\prime}\right), 0<t<1 \\
u(0)=u(1)=0
\end{array}\right.
$$

where $\varphi_{p}(s)=|s|^{p-2} s, p>1$. The singularity may occur at $u=0, t=0$ and $t=1$, and the function $f$ is allowed to change sign. Note $f$ may not be a Carathéodory function because of the singular behavior of the $u$ variable. In the literature $[6,7,10]$, (1.1) has been discussed extensively when $f(t, u, v) \equiv f(t, u)$ and $f$ is positive i.e. $f$ : $(0,1) \times(0, \infty) \rightarrow(0, \infty)$. Recently $[1,11],(1.1)$ was discussed when $f(t, u, v) \equiv f(t, u)$ and $f:(0,1) \times(0, \infty) \rightarrow R$. The case when $f$ depends on the $u^{\prime}$ variable has received very little attention in the literature, see $[2,5]$ and references therein. This paper presents a new and very general existence result for $(1.1)$ when $f:(0,1) \times(0, \infty) \times R \rightarrow R$. Equation of the above form occur in the study of the $p$-Laplace equation, nonNewtonian fluid theory, and the turbulent flow of a gas in a porous medium [9]. The

${ }^{1}$ The research is supported by NNSF of China (10301033). 
case $p=2$ and $p \neq 2$ are quite different. For example, $(i)$ there exists a Green's function when $p=2$ but not if $p \neq 2$; (ii) $\varphi_{p}^{-1}(x)$ is continuously differentiable for $1<p \leq 2$ but $\varphi_{p}^{-1}(x)$ is not continuously differentiable for $p>2$. As a result the argument in the case $p \neq 2$ is more difficult. Other differences between $p=2$ and $p \neq 2$, can be found in [12].

2. General Existence Theorem. First we consider the boundary value problem

$$
\left\{\begin{array}{l}
-\left(\varphi_{p}\left(u^{\prime}\right)\right)^{\prime}=g\left(t, u, u^{\prime}\right), 0<t<1 \\
u(0)=a, u(1)=b
\end{array}\right.
$$

where $g:(0,1) \times R^{2} \rightarrow R$ is continuous and suppose that there exist positive continuous functions $q \in C(0,1)$ and $\Psi:[0,+\infty) \rightarrow(0, \infty)$ with

$$
\int_{0}^{1} q(t) d t<+\infty
$$

and

$$
|g(t, u, v)| \leq q(t) \Psi(|v|) \text { for all }(t, u, v) \in(0,1) \times R^{2} .
$$

For all $\rho \in(0,1]$, define the operator

$$
N_{\rho}: C[0,1] \rightarrow C[0,1]
$$

by

$$
\left(N_{\rho} u\right)(t):=\varphi_{p}^{-1}\left(A_{u}+\rho \int_{0}^{t} g(\tau,(J u)(\tau), u(\tau)) d \tau\right),
$$

where

$$
J(u)(\tau)=b-\int_{\tau}^{1} u(s) d s
$$

for all $0 \leq \tau \leq 1$, and $A_{u} \in(-\infty, \infty)$ is such that

$$
\int_{0}^{1} \varphi_{p}^{-1}\left(A_{u}+\rho \int_{0}^{t} g(\tau,(J u)(\tau), u(\tau)) d \tau\right) d t=b-a .
$$

LEMMA 2.1. [5] (1) $N_{\rho}: C[0,1] \rightarrow C[0,1]$ is completely continuous.

(2) If $\Omega \subset\left\{z \in C[0,1] \mid\left(N_{\rho} z\right)(t)=z(t)\right\}$ and $\sup \left\{\sup _{[0,1]}|z(t)| \mid z \in \Omega\right\}<\infty$, then $\Omega$ is a relatively compact set in $C[0,1]$.

LEMMA 2.2. [11] Let $e_{n}=\left[\frac{1}{2^{n+1}}, 1\right](n \geq 1), e_{0}=\emptyset$. If there exist a sequence $\left\{\varepsilon_{n}\right\} \downarrow 0$ and $\varepsilon_{n}>0$ for $n \geq 1$, then there exist a function $\lambda \in C^{1}[0,1]$ such that

(1) $\varphi_{p}\left(\lambda^{\prime}\right) \in C^{1}[0,1]$ and $\max _{0 \leq t \leq 1}\left|\left(\varphi_{p}\left(\lambda^{\prime}(t)\right)\right)^{\prime}\right|>0$, and

(2) $\lambda(0)=\lambda(1)=0$ and $0<\lambda(t) \leq \varepsilon_{n}, t \in e_{n} \backslash e_{n-1}, n \geq 1$.

We next present a general existence theorem for BVP (1.1). 
THEOREM 2.1. Let $n_{0} \in\{1,2, \ldots\}$ be fixed and suppose the following conditions are satisfied:

$$
f:(0,1) \times(0, \infty) \times R \rightarrow R \text { is continuous }
$$

$\left\{\begin{array}{l}\text { let } n \in\left\{n_{0}, n_{0}+1, \ldots\right\} \equiv N_{0} \text { and associated with each } n \in N_{0} \\ \text { we have a constant } \rho_{n} \text { such that }\left\{\rho_{n}\right\} \text { is a nonincreasing } \\ \text { sequence with } \lim _{n \rightarrow \infty} \rho_{n}=0 \text { and such that for } \\ \frac{1}{2^{n+1}} \leq t \leq 1 \text { and } v \in R \text { we have } f\left(t, \rho_{n}, v\right) \geq 0\end{array}\right.$

$\left\{\begin{array}{l}\exists \alpha \in C[0,1] \cap C^{1}(0,1), \varphi_{p}\left(\alpha^{\prime}\right) \in C^{1}(0,1), \alpha(0)=0=\alpha(1), \\ \alpha>0 \text { on }(0,1) \text { such that } \\ -\left(\varphi_{p}\left(\alpha^{\prime}\right)\right)^{\prime} \leq f(t, \alpha(t), v) \text { for }(t, v) \in(0,1) \times R\end{array}\right.$

and

$$
\left\{\begin{array}{l}
\exists \beta \in C^{1}[0,1],\left(\varphi_{p}\left(\beta^{\prime}\right)\right)^{\prime} \in C(0,1), \\
\text { with } \beta(t) \geq \alpha(t), \beta(t) \geq \rho_{n_{0}} \text { for } t \in[0,1] \text { and } \\
-\left(\varphi_{p}\left(\beta^{\prime}\right)\right)^{\prime} \geq f\left(t, \beta(t), \beta^{\prime}(t)\right) \text { for } t \in(0,1) \text { and } \\
-\left(\varphi_{p}\left(\beta^{\prime}\right)\right)^{\prime} \geq f\left(\frac{1}{2^{n_{0}+1}}, \beta(t), \beta^{\prime}(t)\right) \text { for } t \in\left(0, \frac{1}{2^{n_{0}+1}}\right)
\end{array}\right.
$$

$$
\left\{\begin{array}{l}
\text { there exist } q \in C(0,1) \text { and } \\
\text { for any } 0<\varepsilon<a_{0}=\sup _{t \in[0,1]} \beta(t), \text { there exists continuous function } \\
\Psi_{\varepsilon}:[0, \infty) \rightarrow(0, \infty) \text { such that } \\
|f(t, u, v)| \leq q(t) \Psi_{\varepsilon}(|v|) \text { for }(t, u, v) \in(0,1) \times\left[\varepsilon, a_{0}\right] \times R \\
\int_{0}^{1} q(s) d s<\infty \text { and } \int_{0}^{1} q(s) d s<\int_{0}^{\infty} \frac{d u}{\Psi_{\varepsilon}\left(\varphi_{p}^{-1}(u)\right)}
\end{array}\right.
$$

where $\varphi_{p}^{-1}$ is the inverse function of $\varphi_{p}$. Then (1.1) has a solution $u \in C[0,1] \cap$ $C^{1}(0,1),\left(\varphi_{p}\left(u^{\prime}\right)\right)^{\prime} \in C(0,1)$ with $\alpha(t) \leq u(t) \leq \beta(t)$ for $t \in[0,1]$.

Proof. For $n=n_{0}, n_{0}+1, \ldots$ let

$$
e_{n}=\left[\frac{1}{2^{n+1}}, 1\right] \text { and } \theta_{n}(t)=\max \left\{\frac{1}{2^{n+1}}, t\right\}, 0 \leq t \leq 1
$$

and

$$
f_{n}(t, x, y)=\max \left\{f\left(\theta_{n}(t), x, y\right), f(t, x, y)\right\} .
$$

Next we define inductively

$$
g_{n_{0}}(t, x, y)=f_{n_{0}}(t, x, y)
$$

and

$$
g_{n}(t, x, y)=\min \left\{f_{n_{0}}(t, x, y), \ldots, f_{n}(t, x, y)\right\}, n=n_{0}+1, n_{0}+2, \ldots
$$

Notice

$$
f(t, x, y) \leq \ldots \leq g_{n+1}(t, x, y) \leq g_{n}(t, x, y) \leq \ldots \leq g_{n_{0}}(t, x, y)
$$


for $(t, x, y) \in(0,1] \times(0, \infty) \times R$ and

$$
g_{n}(t, x, y)=f(t, x, y) \text { for }(t, x, y) \in e_{n} \times(0, \infty) \times R .
$$

Without loss of generality assume $\rho_{n_{0}} \leq \min _{t \in\left[\frac{1}{3}, \frac{2}{3}\right]} \alpha(t)$. Fix $n \in\left\{n_{0}, n_{0}+1, \ldots\right\}$. Let $t_{n} \in\left[0, \frac{1}{3}\right]$ and $s_{n} \in\left[\frac{2}{3}, 1\right]$ be such that

$$
\alpha\left(t_{n}\right)=\alpha\left(s_{n}\right)=\rho_{n} \text { and } \alpha(t) \leq \rho_{n} \text { for } t \in\left[0, t_{n}\right] \cup\left[s_{n}, 1\right]
$$

Define

$$
\alpha_{n}(t)=\left\{\begin{array}{l}
\rho_{n} \text { if } t \in\left[0, t_{n}\right] \cup\left[s_{n}, 1\right] \\
\alpha(t) \text { if } t \in\left(t_{n}, s_{n}\right) .
\end{array}\right.
$$

We begin with the boundary value problem

$$
\left\{\begin{array}{l}
-\left(\varphi_{p}\left(u^{\prime}\right)\right)^{\prime}=g_{n_{0}}^{*}\left(t, u, u^{\prime}\right), 0<t<1 \\
u(0)=u(1)=\rho_{n_{0}}
\end{array}\right.
$$

where

$$
g_{n_{0}}^{*}(t, u, v)=\left\{\begin{array}{l}
g_{n_{0}}\left(t, \alpha_{n_{0}}, v^{*}\right)+r\left(\alpha_{n_{0}}-u\right), u(t) \leq \alpha_{n_{0}}(t) \\
g_{n_{0}}\left(t, u, v^{*}\right), \quad \alpha_{n_{0}}(t) \leq u(t) \leq \beta(t) \\
g_{n_{0}}\left(t, \beta, v^{*}\right)+r(\beta-u), u(t) \geq \beta(t)
\end{array}\right.
$$

with

$$
v^{*}=\left\{\begin{array}{l}
M_{n_{0}}, v>M_{n_{0}} \\
v,-M_{n_{0}} \leq v \leq M_{n_{0}} \\
-M_{n_{0}}, v<-M_{n_{0}}
\end{array}\right.
$$

and $r: R \rightarrow[-1,1]$ is the radial retraction defined by

$$
r(u)=\left\{\begin{array}{l}
u, \quad|u| \leq 1 \\
\frac{u}{|u|}, \quad|u|>1,
\end{array}\right.
$$

and $M_{n_{0}} \geq \sup _{[0,1]}\left|\beta^{\prime}(t)\right|$ is such that (with $\varepsilon=\min _{[0,1]} \alpha_{n_{0}}(t)$ )

$$
\int_{0}^{\varphi_{p}\left(M_{n_{0}}\right)} \frac{d u}{\Psi_{\varepsilon}\left(\varphi_{p}^{-1}(u)\right)}>\int_{0}^{1} q(s) d s .
$$

From [5], we know problem (2.6) has a solution $u_{n_{0}} \in C^{1}[0,1]$ with $\left(\varphi_{p}\left(u_{n_{0}}^{\prime}\right)\right)^{\prime} \in C(0,1)$. We first show

$$
u_{n_{0}}(t) \geq \alpha_{n_{0}}(t) \text { for } t \in[0,1]
$$

Suppose (2.8) is not true. Then $u_{n_{0}}-\alpha_{n_{0}}$ has a negative absolute minimum at $\tau \in$ $(0,1)$. Now since $u_{n_{0}}(0)-\alpha_{n_{0}}(0)=0=u_{n_{0}}(1)-\alpha_{n_{0}}(1)$ there exists $\tau_{0}, \tau_{1} \in[0,1]$ with 
$\tau \in\left(\tau_{0}, \tau_{1}\right)$ and

$$
u_{n_{0}}\left(\tau_{0}\right)-\alpha_{n_{0}}\left(\tau_{0}\right)=u_{n_{0}}\left(\tau_{1}\right)-\alpha_{n_{0}}\left(\tau_{1}\right)=0
$$

and

$$
u_{n_{0}}(t)-\alpha_{n_{0}}(t)<0, t \in\left(\tau_{0}, \tau_{1}\right)
$$

We now claim

$$
\left(\varphi_{p}\left(u_{n_{0}}^{\prime}\right)\right)^{\prime}-\left(\varphi_{p}\left(\alpha_{n_{0}}^{\prime}\right)\right)^{\prime}<0 \text { for a.e. } t \in\left(\tau_{0}, \tau_{1}\right) .
$$

If (2.9) is true, then (2.8) holds. Let

$$
w_{n_{0}}(t)=u_{n_{0}}(t)-\alpha_{n_{0}}(t)<0 \text { for } t \in\left(\tau_{0}, \tau_{1}\right) .
$$

Then

$$
\int_{\tau_{0}}^{\tau_{1}}\left(\left(\varphi_{p}\left(u_{n_{0}}^{\prime}\right)\right)^{\prime}-\left(\varphi_{p}\left(\alpha_{n_{0}}^{\prime}\right)\right)^{\prime}\right) w_{n_{0}}(t) d t \geq 0 .
$$

On the other hand, using the inequality

$$
\left(\varphi_{p}(b)-\varphi_{p}(a)\right)(b-a) \geq 0 \text { for } a, b \in R
$$

and the fact that there exists $\tau^{*} \in\left(\tau_{0}, \tau_{1}\right)$ with $u_{n_{0}}^{\prime}\left(\tau^{*}\right) \neq \alpha_{n_{0}}^{\prime}\left(\tau^{*}\right)$, we have

$$
\begin{aligned}
& \int_{\tau_{0}}^{\tau_{1}}\left(\left(\varphi_{p}\left(u_{n_{0}}^{\prime}\right)\right)^{\prime}(t)-\left(\varphi_{p}\left(\alpha_{n_{0}}^{\prime}\right)\right)^{\prime}(t)\right) w_{n_{0}}(t) d t \\
= & -\int_{\tau_{0}}^{\tau_{1}}\left(\varphi_{p}\left(u_{n_{0}}^{\prime}(t)\right)-\varphi_{p}\left(\alpha_{n_{0}}^{\prime}(t)\right)\right)\left(u_{n_{0}}^{\prime}(t)-\alpha_{n_{0}}^{\prime}(t)\right) d t \\
< & 0,
\end{aligned}
$$

which is a contradiction. As a result if we show that (2.9) is true then (2.8) will follow.

To see that (2.9) is true we will in fact prove more, i.e., we will prove that

$$
\left(\varphi_{p}\left(u_{n_{0}}^{\prime}\right)\right)^{\prime}(t)-\left(\varphi_{p}\left(\alpha_{n_{0}}^{\prime}\right)\right)^{\prime}(t)<0 \text { for } t \in\left(\tau_{0}, \tau_{1}\right) \text { provided } t \neq t_{n_{0}} \text { or } t \neq s_{n_{0}} .
$$

Fix $t \in\left(\tau_{0}, \tau_{1}\right)$ and assume $t \neq t_{n_{0}}$ or $t \neq s_{n_{0}}$. Then

$$
\begin{aligned}
& \left(\varphi_{p}\left(u_{n_{0}}^{\prime}\right)\right)^{\prime}(t)-\left(\varphi_{p}\left(\alpha_{n_{0}}^{\prime}\right)\right)^{\prime}(t) \\
& \quad=-\left[g_{n_{0}}\left(t, \alpha_{n_{0}}(t),\left(u_{n_{0}}^{\prime}(t)\right)^{*}\right)+r\left(\alpha_{n_{0}}(t)-u_{n_{0}}(t)\right)+\left(\varphi_{p}\left(\alpha_{n_{0}}^{\prime}\right)\right)^{\prime}(t)\right] \\
& \quad=\left\{\begin{array}{l}
-\left[g_{n_{0}}\left(t, \alpha(t),\left(u_{n_{0}}^{\prime}(t)\right)^{*}\right)+r\left(\alpha(t)-u_{n_{0}}(t)\right)+\left(\varphi_{p}\left(\alpha^{\prime}\right)\right)^{\prime}(t)\right] \text { if } t \in\left(t_{n_{0}}, s_{n_{0}}\right) \\
-\left[g_{n_{0}}\left(t, \rho_{n_{0}},\left(u_{n_{0}}^{\prime}(t)\right)^{*}\right)+r\left(\rho_{n_{0}}-u_{n_{0}}(t)\right)\right] \text { if } t \in\left(0, t_{n_{0}}\right) \cup\left(s_{n_{0}}, 1\right) .
\end{array}\right.
\end{aligned}
$$

Case (1). $t \in\left[\frac{1}{2^{n_{0}+1}}, 1\right)$.

Then since $g_{n_{0}}(t, u, v)=f(t, u, v)$ for $(u, v) \in(0, \infty) \times R$ (note $\left.t \in e_{n_{0}}\right)$ we have

$$
\begin{aligned}
& \left(\varphi_{p}\left(u_{n_{0}}^{\prime}\right)\right)^{\prime}(t)-\left(\varphi_{p}\left(\alpha_{n_{0}}^{\prime}\right)\right)^{\prime}(t) \\
& \quad=\left\{\begin{array}{l}
-\left[f\left(t, \alpha(t),\left(u_{n_{0}}^{\prime}(t)\right)^{*}\right)+r\left(\alpha(t)-u_{n_{0}}(t)\right)+\left(\varphi_{p}\left(\alpha^{\prime}\right)\right)^{\prime}(t)\right] \text { if } t \in\left(t_{n_{0}}, s_{n_{0}}\right) \\
-\left[f\left(t, \rho_{n_{0}},\left(u_{n_{0}}^{\prime}(t)\right)^{*}\right)+r\left(\rho_{n_{0}}-u_{n_{0}}(t)\right)\right] \text { if } t \in\left(0, t_{n_{0}}\right) \cup\left(s_{n_{0}}, 1\right)
\end{array}\right. \\
& \quad<0,
\end{aligned}
$$

from (2.2) and (2.3). 
Case (2). $t \in\left(0, \frac{1}{2^{n_{0}+1}}\right)$.

Then since

$$
g_{n_{0}}(t, u, v)=\max \left\{f\left(\frac{1}{2^{n_{0}+1}}, u, v\right), f(t, u, v)\right\}
$$

we have $g_{n_{0}}(t, u, v) \geq f(t, u, v)$ and $g_{n_{0}}(t, u, v) \geq f\left(\frac{1}{2^{n_{0}+1}}, u, v\right)$ for $(u, v) \in(0, \infty) \times R$. Thus we have

$$
\begin{aligned}
& \left(\varphi_{p}\left(u_{n_{0}}^{\prime}\right)\right)^{\prime}(t)-\left(\varphi_{p}\left(\alpha_{n_{0}}^{\prime}\right)\right)^{\prime}(t) \\
& \quad \leq\left\{\begin{array}{l}
-\left[f\left(t, \alpha(t),\left(u_{n_{0}}^{\prime}(t)\right)^{*}\right)+r\left(\alpha(t)-u_{n_{0}}(t)\right)+\left(\varphi_{p}\left(\alpha^{\prime}\right)\right)^{\prime}(t)\right] \text { if } t \in\left(t_{n_{0}}, s_{n_{0}}\right) \\
-\left[f\left(\frac{1}{2^{n_{0}+1}}, \rho_{n_{0}},\left(u_{n_{0}}^{\prime}(t)\right)^{*}\right)+r\left(\rho_{n_{0}}-u_{n_{0}}(t)\right)\right] \text { if } t \in\left(0, t_{n_{0}}\right) \cup\left(s_{n_{0}}, 1\right)
\end{array}\right. \\
& \quad<0,
\end{aligned}
$$

from (2.2) and (2.3).

Now case (1) and (2) guarantee that (2.9) holds, so (2.8) is satisfied. Thus

$$
\alpha(t) \leq \alpha_{n_{0}}(t) \leq u_{n_{0}}(t) \text { for } t \in[0,1]
$$

Next we show

$$
u_{n_{0}}(t) \leq \beta(t) \text { for } t \in[0,1]
$$

If (2.11) is not true then $u_{n_{0}}-\beta$ would have a positive absolute maximum at say $\tau_{0} \in(0,1)$, in which case $\left(u_{n_{0}}-\beta\right)^{\prime}\left(\tau_{0}\right)=0$ and

$$
\left(\varphi_{p}\left(u_{n_{0}}^{\prime}\right)\right)^{\prime}\left(\tau_{0}\right)-\left(\varphi_{p}\left(\beta^{\prime}\right)\right)^{\prime}\left(\tau_{0}\right) \leq 0
$$

See the proof in [5].

There are two cases to consider, namely $\tau_{0} \in\left[\frac{1}{2^{n_{0}+1}}, 1\right)$ and $\tau_{0} \in\left(0, \frac{1}{2^{n_{0}+1}}\right)$.

Case (1). $\tau_{0} \in\left[\frac{1}{2^{n_{0}+1}}, 1\right)$.

Then $u_{n_{0}}\left(\tau_{0}\right)>\beta\left(\tau_{0}\right), u_{n_{0}}^{\prime}\left(\tau_{0}\right)=\beta^{\prime}\left(\tau_{0}\right)$ together with $g_{n_{0}}\left(\tau_{0}, u, v\right)=f\left(\tau_{0}, u, v\right)$ for $(u, v) \in(0, \infty) \times R$ and $M_{n_{0}} \geq \sup _{[0,1]}\left|\beta^{\prime}(t)\right|$ gives

$$
\begin{aligned}
& \left(\varphi_{p}\left(u_{n_{0}}^{\prime}\right)\right)^{\prime}\left(\tau_{0}\right)-\left(\varphi_{p}\left(\beta^{\prime}\right)\right)^{\prime}\left(\tau_{0}\right) \\
& \quad=-\left[g_{n_{0}}\left(\tau_{0}, \beta\left(\tau_{0}\right),\left(u_{n_{0}}^{\prime}\left(\tau_{0}\right)\right)^{*}\right)+r\left(\beta\left(\tau_{0}\right)-u_{n_{0}}\left(\tau_{0}\right)\right)\right]-\left(\varphi_{p}\left(\beta^{\prime}\right)\right)^{\prime}\left(\tau_{0}\right) \\
& \quad=-\left[\left(\varphi_{p}\left(\beta^{\prime}\right)\right)^{\prime}\left(\tau_{0}\right)+f\left(\tau_{0}, \beta\left(\tau_{0}\right), \beta^{\prime}\left(\tau_{0}\right)\right)\right]-r\left(\beta\left(\tau_{0}\right)-u_{n_{0}}\left(\tau_{0}\right)\right) \\
& \quad>0
\end{aligned}
$$

from (2.4), which is a contradiction.

Case (2). $\tau_{0} \in\left(0, \frac{1}{2^{n_{0}+1}}\right)$.

Then $u_{n_{0}}\left(\tau_{0}\right)>\beta\left(\tau_{0}\right)$ together with

$$
g_{n_{0}}\left(\tau_{0}, u, v\right)=\max \left\{f\left(\frac{1}{2^{n_{0}+1}}, u, v\right), f\left(\tau_{0}, u, v\right)\right\}
$$


for $(u, v) \in(0, \infty) \times R$ gives

$$
\begin{aligned}
\left(\varphi_{p}\left(u_{n_{0}}^{\prime}\right)\right)^{\prime}\left(\tau_{0}\right)-\left(\varphi_{p}\left(\beta^{\prime}\right)\right)^{\prime}\left(\tau_{0}\right) & \\
= & -\left[\max \left\{f\left(\frac{1}{2^{n_{0}+1}}, \beta\left(\tau_{0}\right), \beta^{\prime}\left(\tau_{0}\right)\right), f\left(\tau_{0}, \beta\left(\tau_{0}\right), \beta^{\prime}\left(\tau_{0}\right)\right)\right\}+r\left(\beta\left(\tau_{0}\right)-u_{n_{0}}\left(\tau_{0}\right)\right)\right] \\
& -\left(\varphi_{p}\left(\beta^{\prime}\right)\right)^{\prime}\left(\tau_{0}\right)>0
\end{aligned}
$$

from (2.4), which is a contradiction.

Thus (2.11) holds. Next we show that

$$
\left|u_{n_{0}}^{\prime}\right|_{\infty}=\sup _{t \in[0,1]}\left|u_{n_{0}}^{\prime}(t)\right| \leq M_{n_{0}} .
$$

Suppose that (2.13) is false. Let $\varepsilon=\min _{[0,1]} \alpha_{n_{0}}(t)$. Without loss of generality assume $u_{n_{0}}^{\prime}(t) \not \leq M_{n_{0}}$ for some $t \in[0,1]$. Then since $u_{n_{0}}(0)=u_{n_{0}}(1)=\rho_{n_{0}}$ there exists $\tau_{1} \in(0,1)$ with $u_{n_{0}}^{\prime}\left(\tau_{1}\right)=0$ and so there exists $\tau_{2}, \tau_{3} \in(0,1)$ with $u_{n_{0}}^{\prime}\left(\tau_{3}\right)=0, u_{n_{0}}^{\prime}\left(\tau_{2}\right)=M_{n_{0}}$ and $0 \leq u_{n_{0}}^{\prime}(s) \leq M_{n_{0}}$ for $s$ between $\tau_{3}$ and $\tau_{2}$. Without loss of generality assume $\tau_{3}<\tau_{2}$. Now since $\alpha_{n_{0}}(t) \leq u_{n_{0}}(t) \leq \beta(t)$ for $t \in[0,1]$ and

$$
g_{n_{0}}(t, u, v)=\max \left\{f\left(\frac{1}{2^{n_{0}+1}}, u, v\right), f(t, u, v)\right\}
$$

for $(t, u, v) \in(0,1) \times(0, \infty) \times R$, we have for $s \in\left(\tau_{3}, \tau_{2}\right)$ that

$$
\left(\varphi_{p}\left(u_{n_{0}}^{\prime}\right)\right)^{\prime}\left(\tau_{0}\right) \leq q(s) \Psi_{\varepsilon}\left(u_{n_{0}}^{\prime}(s)\right)
$$

and so

$$
\int_{0}^{\varphi_{p}\left(M_{n_{0}}\right)} \frac{d u}{\Psi_{\varepsilon}\left(\varphi_{p}^{-1}(u)\right)}=\int_{\tau_{3}}^{\tau_{2}} \frac{\left(\varphi_{p}\left(u_{n_{0}}^{\prime}\right)\right)^{\prime}}{\Psi_{\varepsilon}\left(u_{n_{0}}^{\prime}(s)\right)} d s \leq \int_{0}^{1} q(s) d s .
$$

This contradicts (2.7). The other cases are treated similarly. As a result $\alpha(t) \leq u_{n_{0}}(t) \leq$ $\beta(t)$ for $t \in[0,1]$ and $\left|u_{n_{0}}^{\prime}\right|_{\infty} \leq M_{n_{0}}$. Thus $u_{n_{0}}$ satisfies

$$
-\left(\varphi_{p}\left(u_{n_{0}}^{\prime}\right)\right)^{\prime}=g_{n_{0}+1}\left(t, u_{n_{0}}, u_{n_{0}}^{\prime}\right), 0<t<1
$$

Next we consider the boundary value problem

$$
\left\{\begin{array}{l}
-\left(\varphi_{p}\left(u^{\prime}\right)\right)^{\prime}=g_{n_{0}+1}^{*}\left(t, u, u^{\prime}\right), 0<t<1 \\
u(0)=u(1)=\rho_{n_{0}+1}
\end{array}\right.
$$

where

$$
g_{n_{0}+1}^{*}(t, u, v)=\left\{\begin{array}{l}
g_{n_{0}+1}\left(t, \alpha_{n_{0}+1}, v^{*}\right)+r\left(\alpha_{n_{0}+1}-u\right), u(t) \leq \alpha_{n_{0}+1}(t) \\
g_{n_{0}+1}\left(t, u, v^{*}\right), \rho_{n_{0}+1} \leq u(t) \leq u_{n_{0}}(t) \\
g_{n_{0}+1}\left(t, u_{n_{0}}, v^{*}\right)+r\left(u_{n_{0}}-u\right), u(t) \geq u_{n_{0}}(t)
\end{array}\right.
$$

with

$$
v^{*}=\left\{\begin{array}{l}
M_{n_{0}+1}, \quad v>M_{n_{0}+1} \\
v,-M_{n_{0}+1} \leq v \leq M_{n_{0}+1} \\
-M_{n_{0}+1}, \quad v<-M_{n_{0}+1}
\end{array}\right.
$$


here $M_{n_{0}+1} \geq M_{n_{0}}$ is such that (with $\varepsilon=\min _{[0,1]} \alpha_{n_{0}+1}(t)$ ) and $\Psi_{\varepsilon}$ and $q$ are as described in $(2.5)$ )

$$
|f(t, u, v)| \leq q(t) \Psi_{\varepsilon}(|v|) \text { for }(t, u, v) \in(0,1) \times[\varepsilon, \infty) \times R
$$

and

$$
\int_{0}^{1} q(s) d s<\int_{0}^{\varphi_{p}\left(M_{n_{0}+1}\right)} \frac{d u}{\Psi_{\varepsilon}\left(\varphi_{p}^{-1}(u)\right)} .
$$

From [5] we know there exists a solution $u_{n_{0}+1} \in C^{1}[0,1]$ with $\left(\varphi_{p}\left(u_{n_{0}+1}^{\prime}\right)\right)^{\prime} \in C(0,1)$ to (2.14). We first show that

$$
u_{n_{0}+1}(t) \geq \alpha_{n_{0}+1}(t), t \in[0,1] .
$$

Suppose that (2.16) is not true. Then there exists $\tau_{0}, \tau_{1} \in[0,1]$ with

$$
u_{n_{0}+1}\left(\tau_{0}\right)-\alpha_{n_{0}+1}\left(\tau_{0}\right)=u_{n_{0}+1}\left(\tau_{1}\right)-\alpha_{n_{0}+1}\left(\tau_{1}\right)=0
$$

and

$$
u_{n_{0}+1}(t)-\alpha_{n_{0}+1}(t)<0, t \in\left(\tau_{0}, \tau_{1}\right)
$$

If we show

$$
\left(\varphi_{p}\left(u_{n_{0}}^{\prime}\right)\right)^{\prime}-\left(\varphi_{p}\left(\alpha_{n_{0}}^{\prime}\right)\right)^{\prime}<0 \text { for a.e. } t \in\left(\tau_{0}, \tau_{1}\right),
$$

then as before (2.16) is true. Fix $t \in\left(\tau_{0}, \tau_{1}\right)$ and assume $t \neq t_{n_{0}}$ or $t \neq s_{n_{0}}$. Then

$$
\begin{aligned}
& \left(\varphi_{p}\left(u_{n_{0}}^{\prime}\right)\right)^{\prime}(t)-\left(\varphi_{p}\left(\alpha_{n_{0}}^{\prime}\right)\right)^{\prime}(t) \\
& =\left\{\begin{array}{l}
-\left[g_{n_{0}+1}\left(t, \alpha(t),\left(u_{n_{0}+1}^{\prime}(t)\right)^{*}\right)+r\left(\alpha(t)-u_{n_{0}+1}(t)\right)+\left(\varphi_{p}\left(\alpha^{\prime}\right)\right)^{\prime}(t)\right] \text { if } t \in\left(t_{n_{0}+1}, s_{n_{0}+1}\right) \\
-\left[g_{n_{0}+1}\left(t, \rho_{n_{0}+1},\left(u_{n_{0}+1}^{\prime}(t)\right)^{*}\right)+r\left(\rho_{n_{0}+1}-u_{n_{0}+1}(t)\right)\right] \text { if } t \in\left(0, t_{n_{0}+1}\right) \cup\left(s_{n_{0}+1}, 1\right) .
\end{array}\right.
\end{aligned}
$$

Case (1). $t \in\left[\frac{1}{2^{n_{0}+2}}, 1\right)$.

Then since $g_{n_{0}+1}(t, u, v)=f(t, u, v)$ for $(u, v) \in(0, \infty) \times R$ (note $\left.t \in e_{n_{0}+1}\right)$ we have

$$
\begin{aligned}
& \left(\varphi_{p}\left(u_{n_{0}+1}^{\prime}\right)\right)^{\prime}(t)-\left(\varphi_{p}\left(\alpha_{n_{0}+1}^{\prime}\right)\right)^{\prime}(t) \\
& \quad=\left\{\begin{array}{l}
-\left[f\left(t, \alpha(t),\left(u_{n_{0}+1}^{\prime}(t)\right)^{*}\right)+r\left(\alpha(t)-u_{n_{0}+1}(t)\right)+\left(\varphi_{p}\left(\alpha^{\prime}\right)\right)^{\prime}(t)\right] \text { if } t \in\left(t_{n_{0}+1}, s_{n_{0}+1}\right) \\
-\left[f\left(t, \rho_{n_{0}+1},\left(u_{n_{0}+1}^{\prime}(t)\right)^{*}\right)+r\left(\rho_{n_{0}+1}-u_{n_{0}+1}(t)\right)\right] \text { if } t \in\left(0, t_{n_{0}+1}\right) \cup\left(s_{n_{0}+1}, 1\right)
\end{array}\right. \\
& \quad<0,
\end{aligned}
$$

from (2.2) and (2.3).

Case (2). $t \in\left(0, \frac{1}{2^{n+2}}\right)$.

Then since $g_{n_{0}+1}\left(t_{1}, u, v\right)$ equals

$$
\min \left\{\max \left\{f\left(\frac{1}{2^{n_{0}+1}}, u, v\right), f(t, u, v)\right\}, \max \left\{f\left(\frac{1}{2^{n_{0}+2}}, u, v\right), f(t, u, v)\right\}\right\}
$$

we have

$$
g_{n_{0}+1}(t, u, v) \geq f(t, u, v)
$$


and

$$
g_{n_{0}+1}(t, u, v) \geq \min \left\{f\left(\frac{1}{2^{n_{0}+1}}, u, v\right), f\left(\frac{1}{2^{n_{0}+2}}, u, v\right)\right\}
$$

for $(u, v) \in(0, \infty) \times R$. Thus we have

$$
\begin{aligned}
& \left(\varphi_{p}\left(u_{n_{0}+1}^{\prime}\right)\right)^{\prime}(t)-\left(\varphi_{p}\left(\alpha_{n_{0}+1}^{\prime}\right)\right)^{\prime}(t) \\
& \leq\left\{\begin{array}{l}
-\left[f\left(t, \alpha(t),\left(u_{n_{0}+1}^{\prime}(t)\right)^{*}\right)+r\left(\alpha(t)-u_{n_{0}+1}(t)\right)+\left(\varphi_{p}\left(\alpha^{\prime}\right)\right)^{\prime}(t)\right] \\
\text { if } t \in\left(t_{n_{0}+1}, s_{n_{0}+1}\right) \\
-\left[\min \left\{f\left(\frac{1}{2^{n_{0}+1}}, \rho_{n_{0}+1},\left(u_{n_{0}+1}^{\prime}(t)\right)^{*}\right), f\left(\frac{1}{2^{n_{0}+2}}, \rho_{n_{0}+1},\left(u_{n_{0}+1}^{\prime}(t)\right)^{*}\right)\right\}\right. \\
\left.\quad r\left(\rho_{n_{0}+1}-u_{n_{0}+1}(t)\right)\right]
\end{array}\right. \\
& <0 \text {, }
\end{aligned}
$$

from (2.2) and (2.3) since

$$
f\left(\frac{1}{2^{n_{0}+1}}, \rho_{n_{0}+1},\left(u_{n_{0}+1}^{\prime}(t)\right)^{*}\right) \geq 0 \text { and } f\left(\frac{1}{2^{n_{0}+2}}, \rho_{n_{0}+1},\left(u_{n_{0}+1}^{\prime}(t)\right)^{*}\right) \geq 0
$$

because

$$
f\left(t, \rho_{n_{0}+1},\left(u_{n_{0}+1}^{\prime}(t)\right)^{*}\right) \geq 0 \text { for } t \in\left[\frac{1}{2^{n_{0}+2}}, 1\right]
$$

and $\frac{1}{2^{n_{0}+1}} \in\left[\frac{1}{2^{n_{0}+2}}, 1\right]$.

Consequently (2.16) is true. Thus

$$
\alpha(t) \leq \alpha_{n_{0}+1}(t) \leq u_{n_{0}+1}(t) \text { for } t \in[0,1] .
$$

Next we show that

$$
u_{n_{0}+1}(t) \leq u_{n_{0}}(t) \text { for } t \in[0,1]
$$

If (2.19) is not true then $u_{n_{0}+1}-u_{n_{0}}$ would have a positive absolute maximum at say $\tau_{0} \in(0,1)$, in which case $\left(u_{n_{0}+1}-u_{n_{0}}\right)^{\prime}\left(\tau_{0}\right)=0$ and

$$
\left(\varphi_{p}\left(u_{n_{0}+1}^{\prime}\right)\right)^{\prime}\left(\tau_{0}\right)-\left(\varphi_{p}\left(u_{n_{0}}^{\prime}\right)\right)^{\prime}\left(\tau_{0}\right) \leq 0
$$

The proof is as above. Then $u_{n_{0}+1}\left(\tau_{0}\right)>u_{n_{0}}\left(\tau_{0}\right)$ together with $g_{n_{0}}\left(\tau_{0}, u, v\right) \geq$ $g_{n_{0}+1}\left(\tau_{0}, u, v\right)$ for $(u, v) \in(0, \infty) \times R$ gives (note $\left(u_{n_{0}+1}^{\prime}\left(\tau_{0}\right)\right)^{*}=\left(u_{n_{0}}^{\prime}\left(\tau_{0}\right)\right)^{*}=u_{n_{0}}^{\prime}\left(\tau_{0}\right)$ since $M_{n_{0}+1} \geq M_{n_{0}}$ and $\left.\left|u_{n_{0}}^{\prime}\right|_{\infty} \leq M_{n_{0}}\right)$

$$
\begin{aligned}
& \left(\varphi_{p}\left(u_{n_{0}+1}^{\prime}\right)\right)^{\prime}\left(\tau_{0}\right)-\left(\varphi_{p}\left(u_{n_{0}}^{\prime}\right)\right)^{\prime}\left(\tau_{0}\right) \\
& \quad=-\left[g_{n_{0}+1}\left(\tau_{0}, u_{n_{0}}\left(\tau_{0}\right),\left(u_{n_{0}+1}^{\prime}\left(\tau_{0}\right)\right)^{*}\right)+r\left(u_{n_{0}}\left(\tau_{0}\right)-u_{n_{0}+1}\left(\tau_{0}\right)\right)\right]-\left(\varphi_{p}\left(u_{n_{0}}^{\prime}\right)\right)^{\prime}\left(\tau_{0}\right) \\
& \quad \geq-\left[\left(\varphi_{p}\left(u_{n_{0}}^{\prime}\right)\right)^{\prime}\left(\tau_{0}\right)+g_{n_{0}}\left(\tau_{0}, u_{n_{0}}\left(\tau_{0}\right), u_{n_{0}}^{\prime}\left(\tau_{0}\right)\right)\right]-r\left(u_{n_{0}}\left(\tau_{0}\right)-u_{n_{0}+1}\left(\tau_{0}\right)\right) \\
& \quad=-r\left(u_{n_{0}}\left(\tau_{0}\right)-u_{n_{0}+1}\left(\tau_{0}\right)\right) \\
& \quad>0
\end{aligned}
$$


which is a contradiction. Thus (2.19) holds. Next we show that

$$
\left|u_{n_{0}+1}^{\prime}\right|_{\infty} \leq M_{n_{0}+1} .
$$

Essentially the same argument as before guarantees that (2.21) holds. As a result

$$
-\left(\varphi_{p}\left(u_{n_{0}+1}^{\prime}\right)\right)^{\prime}=g_{n_{0}+1}\left(t, u_{n_{0}+1}, u_{n_{0}+1}^{\prime}\right) \text { on }(0,1) .
$$

Now proceed inductively to construct $u_{n_{0}+2}, u_{n_{0}+3}, \cdots$ as follows. Suppose we have $u_{k}$ for some $k \in\left\{n_{0}+1, n_{0}+2\right\}$ with $\alpha(t) \leq \alpha_{k}(t) \leq u_{k}(t) \leq u_{k-1}(t)(\leq \beta(t))$ for $t \in[0,1]$.

Then consider the boundary value problem

$$
\left\{\begin{array}{l}
-\left(\varphi_{p}\left(u^{\prime}\right)\right)^{\prime}=g_{k+1}^{*}\left(t, u, u^{\prime}\right)(0<t<1), \\
u(0)=u(1)=\rho_{k+1}
\end{array}\right.
$$

where

$$
g_{k+1}^{*}(t, u, v)=\left\{\begin{array}{l}
g_{k+1}\left(t, \rho_{k+1}, v^{*}\right)+r\left(\rho_{k+1}-u\right), u(t) \leq \rho_{k+1} \\
g_{k+1}\left(t, u, v^{*}\right), \rho_{k+1} \leq u(t) \leq u_{k}(t) \\
g_{k+1}\left(t, u_{k}, v^{*}\right)+r\left(u_{k}-u\right), u(t) \geq u_{k}(t)
\end{array}\right.
$$

with

$$
v^{*}=\left\{\begin{array}{l}
M_{k+1}, \quad v>M_{k+1} \\
v,-M_{k+1} \leq v \leq M_{k+1} \\
-M_{k+1}, \quad v<-M_{k+1}
\end{array}\right.
$$

here $M_{k+1} \geq M_{k}$ is such that (with $\varepsilon=\min _{[0,1]} \alpha_{k+1}(t)$ and $\Psi_{\varepsilon}$ and $q$ are as described in (2.5))

$$
|f(t, u, v)| \leq q(t) \Psi_{\varepsilon}(|v|) \text { for }(t, u, v) \in(0,1) \times[\varepsilon, \infty) \times R
$$

and

$$
\int_{0}^{1} q(s) d s<\int_{0}^{\varphi_{p}\left(M_{k+1}\right)} \frac{d u}{\Psi_{\varepsilon}\left(\varphi_{p}^{-1}(u)\right)}
$$

There exists a solution $u_{k+1} \in C^{1}[0,1]$ with $\left(\varphi_{p}\left(u_{k}^{\prime}\right)\right)^{\prime} \in C(0,1)$ to $(2.22)$ and essentially the same reasoning as above yields

$$
\alpha(t) \leq \alpha_{k+1}(t) \leq u_{k+1}(t) \leq u_{k}(t),\left|u_{k+1}^{\prime}(t)\right| \leq M_{k+1} \text { for } t \in[0,1]
$$

with

$$
-\left(\varphi_{p}\left(u_{k+1}^{\prime}\right)\right)^{\prime}=g_{k+1}\left(t, u_{k+1}, u_{k+1}^{\prime}\right) \text { for } 0<t<1 .
$$

Now consider the interval $\left[\frac{1}{2^{n_{0}+1}}, 1-\frac{1}{2^{n_{0}+1}}\right]$. We claim that

$$
\left\{\begin{array}{l}
\left\{u_{n}^{(j)}\right\}_{n=n_{0}+1}^{\infty}, j=0,1, \text { is a bounded, equicontinuous } \\
\text { family on }\left[\frac{1}{2^{n_{0}+1}}, 1-\frac{1}{2^{n_{0}+1}}\right] .
\end{array}\right.
$$


First note that

$$
\left|u_{n}\right|_{\infty} \leq\left|u_{n_{0}}\right|_{\infty} \leq \sup _{[0,1]} \beta(t)=a_{0} \text { for } t \in[0,1] \text { and } n \geq n_{0}+1 .
$$

Let

$$
\varepsilon=\min _{t \in\left[\frac{1}{2^{n^{0}+1}}, 1-\frac{1}{2^{n_{0}+1}}\right]} \alpha(t) .
$$

Then (2.5) guarantees the existence of $\Psi_{\varepsilon}$ and $q$ (as described in (2.5)) with

$$
|f(t, u, v)| \leq q(t) \Psi_{\varepsilon}(|v|) \text { for }(t, u, v) \in(0,1) \times[\varepsilon, \infty) \times R .
$$

This implies that

$$
\left|g_{n}\left(t, u_{n}(t), u_{n}^{\prime}(t)\right)\right| \leq q(t) \Psi_{\varepsilon}\left(\left|u_{n}^{\prime}(t)\right|\right) \text { for } t \in[a, b]=\left[\frac{1}{2^{n_{0}+1}}, 1-\frac{1}{2^{n_{0}+1}}\right] \subseteq e_{n_{0}}
$$

and $n \geq n_{0}+1$. As a result

$$
\left|\left(\varphi_{p}\left(u_{n}^{\prime}\right)\right)^{\prime}\right| \leq q(t) \Psi_{\varepsilon}\left(\left|u_{n}^{\prime}(t)\right|\right) \text { for } t \in[a, b] \text { and } n \geq n_{0}+1 .
$$

The mean value theorem implies that there exists $\tau_{1, n} \in(a, b)$ with

$$
\left|u^{\prime}\left(\tau_{1, n}\right)\right|=\frac{|u(b)-u(a)|}{b-a} \leq \frac{2 a_{0}}{b-a}=d_{n_{0}} \text { for } n \geq n_{0} .
$$

Fix $n \geq n_{0}+1$ and let $t \in[a, b]$. Without loss of generality assume that $u_{n}^{\prime}(t)>d_{n_{0}}$. Then there exists $\tau_{1} \in(a, b)$ with $u_{n}^{\prime}\left(\tau_{1}\right)=d_{n_{0}}$ and $u_{n}^{\prime}(s)>d_{n_{0}}$ for $s$ between $\tau_{1}$ and $t$. Without loss of generality assume that $\tau_{1}<t$. From (2.26) we have

$$
\frac{\left(\varphi_{p}\left(u_{n}^{\prime}(s)\right)\right)^{\prime}}{\Psi_{\varepsilon}\left(\left|u_{n}^{\prime}(s)\right|\right)} \leq q(s) \text { for } s \in\left(\tau_{1}, t\right)
$$

so integration from $\tau_{1}$ to $t$ yields

$$
\int_{\varphi_{p}\left(d_{n_{0}}\right)}^{\varphi_{p}\left(u_{n}^{\prime}(t)\right)} \frac{d u}{\Psi_{\varepsilon}\left(\varphi_{p}^{-1}(u)\right)} \leq \int_{0}^{1} q(s) d s .
$$

Let $I_{n_{0}}(z)=\int_{\varphi_{p}\left(d_{n_{0}}\right)}^{\varphi_{p}(z)} \frac{d u}{\Psi_{\varepsilon}\left(\varphi_{p}^{-1}(u)\right)}$, so

$$
\left|u_{n}^{\prime}(t)\right| \leq I_{n_{0}}^{-1}\left(\int_{0}^{1} q(s) d s\right) \equiv R_{n_{0}} .
$$

A similar bound is obtained for the other cases, so

$$
\left|u_{n}^{\prime}(s)\right| \leq R_{n_{0}} \text { for } s \in[a, b]=\left[\frac{1}{2^{n_{0}+1}}, 1-\frac{1}{2^{n_{0}+1}}\right]
$$

and $n \geq n_{0}+1$. Now (2.25), (2.26) and (2.27) guarantee that (2.24) holds. The ArzelaAscoli theorem guarantees the existence of a subsequence $N_{n_{0}}$ of integers and a function 
$z_{n_{0}} \in C^{1}\left[\frac{1}{2^{n_{0}+1}}, 1-\frac{1}{2^{n_{0}+1}}\right]$ with $u_{n}^{(j)}, j=0,1$, converging uniformly to $z_{n_{0}}^{(j)}$ on $\left[\frac{1}{2^{n_{0}+1}}, 1-\right.$ $\left.\frac{1}{2^{n_{0}+1}}\right]$ as $n \rightarrow \infty$ through $N_{n_{0}}$. Similarly

$$
\left\{\begin{array}{l}
\left\{u_{n}^{(j)}\right\}_{n=n_{0}+2}^{\infty}, j=0,1, \text { is a bounded, equicontinuous } \\
\text { family on }\left[\frac{1}{2^{n} 0^{+2}}, 1-\frac{1}{2^{n_{0}+2}}\right]
\end{array}\right.
$$

so there is a subsequence $N_{n_{0}+1}$ of $N_{n_{0}}$ and a function

$$
z_{n_{0}+1} \in C^{1}\left[\frac{1}{2^{n_{0}+2}}, 1-\frac{1}{2^{n_{0}+2}}\right]
$$

with $u_{n}^{(j)}, j=0,1$, converging uniformly to $z_{n_{0}+1}^{(j)}$ on $\left[\frac{1}{2^{n_{0}+2}}, 1-\frac{1}{2^{n_{0}+2}}\right]$ as $n \rightarrow \infty$ through $N_{n_{0}+1}$. Note $z_{n_{0}+1}=z_{n_{0}}$ on $\left[\frac{1}{2^{n_{0}+1}}, 1-\frac{1}{2^{n_{0}+1}}\right]$ since $N_{n_{0}+1} \subseteq N_{n_{0}}$. Proceed inductively to obtain subsequences of integers

$$
N_{n_{0}} \supseteq N_{n_{0}+1} \supseteq \ldots \ldots \supseteq N_{k} \supseteq \ldots \ldots
$$

and functions

$$
z_{k} \in C^{1}\left[\frac{1}{2^{n_{0}+1}}, 1-\frac{1}{2^{n_{0}+1}}\right]
$$

with

$$
u_{n}^{(j)}, j=0,1 \text {, converging uniformly to } z_{k}^{(j)} \text { on }\left[\frac{1}{2^{n_{0}+1}}, 1-\frac{1}{2^{n_{0}+1}}\right]
$$

as $n \rightarrow \infty$ through $N_{k}$, and

$$
z_{k}=z_{k-1} \text { on }\left[\frac{1}{2^{k}}, 1-\frac{1}{2^{k}}\right] .
$$

Define a function $u:[0,1] \rightarrow[0, \infty)$ by $u(t)=z_{k}(t)$ on $\left[\frac{1}{2^{k+1}}, 1-\frac{1}{2^{k+1}}\right]$ and $u(0)=$ $u(1)=0$. Notice $u$ is well defined and

$$
\alpha(t) \leq u(t) \leq u_{n_{0}}(t) \leq \beta(t) \text { for } t \in(0,1) .
$$

Now let $[a, b] \subset(0,1)$, be a compact interval. There is an index $n^{*}$ such that $[a, b] \subset$ $\left[\frac{1}{2^{n+1}}, 1-\frac{1}{2^{n+1}}\right]$ for all $n>n^{*}$ and therefore, for all $n>n^{*}$

$$
-\left(\varphi_{p}\left(u_{n}^{\prime}\right)\right)^{\prime}=f\left(t, u_{n}, u_{n}^{\prime}\right) \text { for } a \leq t \leq b .
$$

On the other hand, $\alpha \in C[0,1], \alpha(t)>0$ for all $0<t<1$ so let $r=\min _{a \leq t \leq b} \alpha(t)>0$. Moreover, (2.5) guarantees that there exists $q$ and $\Psi_{\varepsilon}(|v|)$ (with $\varepsilon=r$ ) such that

$$
|f(t, u, v)| \leq q(t) \Psi_{\varepsilon}(|v|),(t, u, v) \in(0,1) \times[\varepsilon, \infty) \times R .
$$

It is easy to see that there exists a continuous function $\bar{f}:(0,1) \times R^{2} \rightarrow R$ such that

$$
|\bar{f}(t, u, v)| \leq q(t) \Psi_{\varepsilon}(|v|),(t, u, v) \in(0,1) \times R^{2}
$$


and

$$
\bar{f}(t, u, v)=f(t, u, v) \text { for all }(t, u, v) \in(0,1) \times[\varepsilon, \infty) \times R .
$$

It is clear that $u_{n}(t) \geq \varepsilon, a \leq t \leq b$ for all $n \geq n_{0}$. Moreover

$$
-\left(\varphi_{p}\left(u_{n}^{\prime}\right)\right)^{\prime}=\bar{f}\left(t, u_{n}, u_{n}^{\prime}\right) \text { for } a \leq t \leq b .
$$

There exists a subsequence $S$ of $\left\{n^{*}+1, n^{*}+2, \cdots\right\}$ with

$$
\max _{a \leq t \leq b}\left|u_{n}(t)-u(t)\right| \rightarrow 0 \text { and } \max _{a \leq t \leq b}\left|u_{n}^{\prime}(t)-u^{\prime}(t)\right| \rightarrow 0 \text { as } n \rightarrow \infty
$$

Now $\left(\varphi_{p}\left(u^{\prime}\right)\right)^{\prime} \in C[a, b]$ and

$$
-\left(\varphi_{p}\left(u^{\prime}\right)\right)^{\prime}=f\left(t, u, u^{\prime}\right) \text { for } a \leq t \leq b .
$$

Since $[a, b] \subset(0,1)$ is arbitrary, we find that

$$
\left(\varphi_{p}\left(u^{\prime}\right)\right)^{\prime} \in C(0,1) \text { and }-\left(\varphi_{p}\left(u^{\prime}\right)\right)^{\prime}=f\left(t, u, u^{\prime}\right) \text { for } 0<t<1 .
$$

It remains to show $u$ is continuous at 0 and 1 . Let $\varepsilon>0$ be given. Now since $\lim _{n \rightarrow \infty} u_{n}(0)=0$ there exists $n_{1} \in\left\{n_{0}, n_{0}+1, \ldots\right\}$ with $u_{n_{1}}(0)<\frac{\varepsilon}{2}$. Next since $u_{n_{1}} \in$ $C[0,1]$ there exists $\delta_{n_{1}}>0$ with

$$
u_{n_{1}}(t)<\frac{\varepsilon}{2} \text { for } t \in\left[0, \delta_{n_{1}}\right] .
$$

Now for $n \geq n_{1}$ we have, since $\left\{u_{n}(t)\right\}_{n \in N_{0}}$ is nonincreasing for each $t \in[0,1]$,

$$
\alpha(t) \leq u_{n}(t) \leq u_{n_{1}}(t)<\frac{\varepsilon}{2} \text { for } t \in\left[0, \delta_{n_{1}}\right] .
$$

Consequently

$$
\alpha(t) \leq u(t) \leq \frac{\varepsilon}{2}<\varepsilon \text { for } t \in\left(0, \delta_{n_{1}}\right]
$$

and so $u$ is continuous at 0 . Similarly $u$ is continuous at 1 . As a result $u \in C[0,1]$.

Suppose that (2.1)-(2.3), (2.5) hold and in addition assume the following conditions are satisfied:

$$
-\left(\varphi_{p}\left(\alpha^{\prime}\right)\right)^{\prime}<f\left(t, u, \alpha^{\prime}(t)\right) \text { for }(t, u) \in(0,1) \times\{u \in(0, \infty): u<\alpha(t)\}
$$

and

$$
\left\{\begin{array}{l}
\exists \beta \in C^{1}[0,1], \quad\left(\varphi_{p}\left(\beta^{\prime}\right)\right)^{\prime} \in C(0,1), \\
\text { with } \beta(t) \geq \rho_{n_{0}} \text { for } t \in[0,1] \text { and } \\
-\left(\varphi_{p}\left(\beta^{\prime}\right)\right)^{\prime} \geq f\left(t, \beta(t), \beta^{\prime}(t)\right) \text { for } t \in(0,1) \text { and } \\
-\left(\varphi_{p}\left(\beta^{\prime}\right)\right)^{\prime} \geq f\left(\frac{1}{2^{n_{0}+1}}, \beta(t), \beta^{\prime}(t)\right) \text { for } t \in\left(0, \frac{1}{2^{n_{0}+1}}\right)
\end{array}\right.
$$

Then the result in Theorem 2.1 is again true. This follows immediately from Theorem 2.1 once we show that (2.5) holds i.e. once we show that $\beta(t) \geq \alpha(t)$ for $t \in[0,1]$. Suppose it is false. Then $\alpha-\beta$ would have a positive absolute maximum 
at say $\tau_{0} \in(0,1)$, so $(\alpha-\beta)^{\prime}\left(\tau_{0}\right)=0$ and $\left(\varphi_{p}\left(\alpha^{\prime}\right)\right)^{\prime}\left(\tau_{0}\right)-\left(\varphi_{p}\left(\beta^{\prime}\right)\right)^{\prime}\left(\tau_{0}\right) \leq 0$. Now $\alpha\left(\tau_{0}\right)>\beta\left(\tau_{0}\right)$ and (2.28) implies that

$$
f\left(\tau_{0}, \beta\left(\tau_{0}\right), \beta^{\prime}\left(\tau_{0}\right)\right)+\left(\varphi_{p}\left(\alpha^{\prime}\right)\right)^{\prime}\left(\tau_{0}\right)=f\left(\tau_{0}, \beta\left(\tau_{0}\right), \alpha^{\prime}\left(\tau_{0}\right)\right)+\left(\varphi_{p}\left(\alpha^{\prime}\right)\right)^{\prime}\left(\tau_{0}\right)>0,
$$

and this together with (2.29) yields the inequality

$$
\left(\varphi_{p}\left(\alpha^{\prime}\right)\right)^{\prime}\left(\tau_{0}\right)-\left(\varphi_{p}\left(\beta^{\prime}\right)\right)^{\prime}\left(\tau_{0}\right) \geq\left(\varphi_{p}\left(\alpha^{\prime}\right)\right)^{\prime}\left(\tau_{0}\right)+f\left(\tau_{0}, \beta\left(\tau_{0}\right), \beta^{\prime}\left(\tau_{0}\right)\right)>0
$$

which is a contradiction. Thus we have the following result.

COROLlaRY 2.2. Let $n_{0} \in\{1,2, \ldots\}$ be fixed and suppose (2.1)-(2.3), (2.5), (2.28) and (2.29) hold. Then (1.1) has a solution $u \in C[0,1] \cap C^{1}(0,1)$ with $\left(\varphi_{p}\left(u^{\prime}\right)\right)^{\prime} \in C(0,1)$ and with $\alpha(t) \leq u(t) \leq \beta(t)$ for $t \in[0,1]$.

REMARK 2.1. (i) If in (2.2) we replace $\frac{1}{2^{n+1}} \leq t \leq 1$ with $0 \leq t \leq 1-\frac{1}{2^{n+1}}$ then one would replace $(2.4)$ with

$$
\left\{\begin{array}{l}
\exists \beta \in C^{1}[0,1],\left(\varphi_{p}\left(\beta^{\prime}\right)\right)^{\prime} \in C(0,1), \\
\text { with } \beta(t) \geq \alpha(t), \beta(t) \geq \rho_{n_{0}} \text { for } t \in[0,1] \text { and } \\
-\left(\varphi_{p}\left(\beta^{\prime}\right)\right)^{\prime} \geq f\left(t, \beta(t), \beta^{\prime}(t)\right) \text { for } t \in(0,1) \text { and } \\
-\left(\varphi_{p}\left(\beta^{\prime}\right)\right)^{\prime} \geq f\left(1-\frac{1}{2^{n_{0}+1}}, \beta(t), \beta^{\prime}(t)\right) \text { for } t \in\left(1-\frac{1}{2^{n_{0}+1}}, 1\right)
\end{array}\right.
$$

(ii) If in (2.2) we replace $\frac{1}{2^{n+1}} \leq t \leq 1$ with $\frac{1}{2^{n+1}} \leq t \leq 1-\frac{1}{2^{n+1}}$ then one would replace (2.4) with

$$
\left\{\begin{array}{l}
\exists \beta \in C^{1}[0,1],\left(\varphi_{p}\left(\beta^{\prime}\right)\right)^{\prime} \in C(0,1), \\
\text { with } \beta(t) \geq \alpha(t), \beta(t) \geq \rho_{n_{0}} \text { for } t \in[0,1] \text { and } \\
-\left(\varphi_{p}\left(\beta^{\prime}\right)\right)^{\prime} \geq f\left(t, \beta(t), \beta^{\prime}(t)\right) \text { for } t \in(0,1) \text { and } \\
-\left(\varphi_{p}\left(\beta^{\prime}\right)\right)^{\prime} \geq f\left(\frac{1}{2^{n_{0}+1}}, \beta(t), \beta^{\prime}(t)\right) \text { for } t \in\left(0, \frac{1}{2^{n_{0}+1}}\right) \\
-\left(\varphi_{p}\left(\beta^{\prime}\right)\right)^{\prime} \geq f\left(1-\frac{1}{2^{n^{+1}}}, \beta(t), \beta^{\prime}(t)\right) \text { for } t \in\left(1-\frac{1}{2^{n_{0}+1}}, 1\right) .
\end{array}\right.
$$

This is clear once one change the definition of $e_{n}$ and $\theta_{n}$. For example in case (ii), take

$$
e_{n}=\left[\frac{1}{2^{n+1}}, 1-\frac{1}{2^{n+1}}\right] \text { and } \theta_{n}(t)=\max \left\{\frac{1}{2^{n+1}}, \min \left\{t, 1-\frac{1}{2^{n+1}}\right\}\right\} .
$$

3. Construction of $\alpha$ and $\beta$. Suppose the following condition is satisfied:

$$
\left\{\begin{array}{l}
\text { let } n \in\left\{n_{0}, n_{0}+1, \ldots\right\} \text { and associated with each } n \text { we } \\
\text { have a constant } \rho_{n} \text { such that }\left\{\rho_{n}\right\} \text { is a decreasing } \\
\text { sequence with } \lim _{n \rightarrow \infty} \rho_{n}=0 \text { and there exists a constant } \\
k_{0}>0 \text { such that for } \frac{1}{2^{n+1}} \leq t \leq 1,0<u \leq \rho_{n} \text { and } v \in R \text { we have } \\
f(t, u, v)>k_{0} .
\end{array}\right.
$$

We will show if (3.1) holds then (2.3) (and of course (2.2)) and (2.28) are satisfied. 
Using Lemma 2.2, we know there exists a function $\lambda \in C^{1}[0,1]$ such that $\varphi_{p}\left(\lambda^{\prime}\right) \in$ $C^{1}[0,1], \lambda(0)=\lambda(1)=0, M=\max _{0 \leq t \leq 1}\left|\left(\varphi_{p}\left(\lambda^{\prime}(t)\right)\right)^{\prime}\right|>0$ and

$$
0<\lambda(t) \leq \rho_{n}, t \in e_{n} \backslash e_{n-1} \text { for } n \geq 1 .
$$

Let $r=\sup _{[0,1]}\left|\lambda^{\prime}(t)\right|$. From (3.1) there exists $k_{0}>0$ with

$$
f(t, u, v)>k_{0} \text { for } t \in(0,1), 0<u<\lambda(t) \text { and } v \in R .
$$

Let

$$
m=\min \left\{1,\left(\frac{k_{0}}{M}\right)^{\frac{1}{p-1}}\right\} .
$$

Let $\alpha(t) \equiv m \lambda(t)$ for $t \in[0,1]$. Then

$$
\begin{aligned}
\left|\left(\varphi_{p}\left(\alpha^{\prime}\right)\right)^{\prime}\right| & =\varphi_{p}(m)\left|\left(\varphi_{p}\left(\lambda^{\prime}\right)\right)^{\prime}\right| \\
& \leq \varphi_{p}(m) M \\
& \leq \frac{k_{0}}{M} M=k_{0},
\end{aligned}
$$

so

$$
\left(\varphi_{p}\left(\alpha^{\prime}\right)\right)^{\prime}+f(t, \alpha(t), v) \geq k_{0}-k_{0}=0 \text { for }(t, v) \in(0,1) \times R
$$

i.e. (2.3) is satisfied. On the other hand

$$
\begin{aligned}
\left(\varphi_{p}\left(\alpha^{\prime}\right)\right)^{\prime}+f\left(t, u, \alpha^{\prime}(t)\right) & \geq f\left(t, u, \alpha^{\prime}(t)\right)-k_{0} \\
& >k_{0}-k_{0} \\
& =0 \text { for }(t, u) \in(0,1) \times\{u \in(0, \infty): u<\alpha(t)\},
\end{aligned}
$$

so (2.28) is satisfied.

Now we discuss the existence of an upper solution $\beta$.

Consider the following conditions:

$\left\{\begin{array}{l}\text { there exist continuous functions } q:(0,1) \rightarrow[0, \infty), \Psi:[0, \infty) \rightarrow(0, \infty) \text { and } \\ \text { there exist } h>0 \text { continuous and nondecreasing on }[0, \infty) \text { such that } \\ |f(t, u, v)| \leq q(t) h(u) \Psi(|v|) \text { for }(t, u, v) \in(0,1] \times\left[\rho_{n_{0}}, \infty\right) \times R\end{array}\right.$

$$
\left\{\begin{array}{c}
\text { there exist } M>\rho_{n_{0}} \text { and } N>0 \text { such that } \\
h(M) \int_{0}^{1} q(s) d s<\int_{0}^{\varphi_{p}(N)} \frac{d u}{\Psi\left(\varphi_{p}^{-1}(u)\right)} \\
M-\rho_{n_{0}}>\varphi_{p}^{-1}(C h(M)) b_{0}
\end{array}\right.
$$

where

$$
\left\{\begin{array}{l}
b_{0}=\max \left\{\int_{0}^{\frac{1}{2}} \varphi_{p}^{-1}\left(\int_{s}^{\frac{1}{2}} q(r) d r\right) d s, \int_{\frac{1}{2}}^{1} \varphi_{p}^{-1}\left(\int_{\frac{1}{2}}^{s} q(r) d r\right) d s\right\} \text { and } \\
C=\max _{-N \leq v \leq N} \Psi(|v|)
\end{array}\right.
$$




$$
\left\{\begin{array}{l}
\text { for any } \varepsilon>0, \text { there exists a continuous function } \\
\Psi_{\varepsilon}:[0, \infty) \rightarrow(0, \infty) \text { such that } \\
|f(t, u, v)| \leq q(t) \Psi_{\varepsilon}(|z|) \text { for }(t, u, v) \in(0,1) \times[\varepsilon, M] \times R, \\
\int_{0}^{1} q(s) d s<\infty \text { and } \int_{0}^{1} q(s) d s<\int_{0}^{\infty} \frac{d u}{\Psi_{\varepsilon}\left(\varphi_{p}^{-1}(u)\right)}
\end{array}\right.
$$

and

$f(t, u, v)$ is nonincreasing on $\left(0, \frac{1}{2^{n_{0}+1}}\right)$ for each fixed $(u, v) \in\left[\rho_{n_{0}}, M\right] \times[-N, N]$.

We show if conditions (3.3)-(3.5), (3.7), (3.8) (here $b_{0}$ and $C$ are as in (3.6)) hold then (2.4) and (2.5) hold.

Consider the problem

$$
\left\{\begin{array}{l}
-\left(\varphi_{p}\left(u^{\prime}\right)\right)^{\prime}=f^{*}\left(t, u, u^{\prime}\right), 0<t<1 \\
u(0)=u(1)=\rho_{n_{0}}
\end{array}\right.
$$

where

$$
f^{*}(t, u, v)=\left\{\begin{array}{l}
f\left(t, \rho_{n_{0}}, v^{*}\right)+r\left(\rho_{n_{0}}-u\right), u \leq \rho_{n_{0}} \\
f\left(t, u, v^{*}\right), \quad \rho_{n_{0}} \leq u \leq M \\
f\left(t, M, v^{*}\right)+r(M-u), u \geq M
\end{array}\right.
$$

with

$$
v^{*}=\left\{\begin{array}{l}
N, v>N \\
v,-N \leq v \leq N \\
-N, v<-N
\end{array}\right.
$$

From [5] we know that (3.9) has a solution $u \in C^{1}[0,1]$ with $\left(\varphi_{p}\left(u^{\prime}\right)\right)^{\prime} \in C(0,1)$. We first show that

$$
u(t) \geq \rho_{n_{0}}, t \in[0,1] .
$$

Suppose that (3.10) is not true. Then there exists a $t_{0} \in(0,1)$ with $u\left(t_{0}\right)<\rho_{n_{0}}, u^{\prime}\left(t_{0}\right)=0$ and

$$
\left(\varphi_{p}\left(u^{\prime}\right)\right)^{\prime}\left(t_{0}\right) \geq 0
$$

However note

$$
\begin{aligned}
\left(\varphi_{p}\left(u^{\prime}\right)\right)^{\prime}\left(t_{0}\right) & =-\left[f\left(t_{0}, \rho_{n_{0}},\left(u^{\prime}\left(t_{0}\right)\right)^{*}\right)+r\left(\rho_{n_{0}}-u\left(t_{0}\right)\right)\right] \\
& =-\left[f\left(t_{0}, \rho_{n_{0}}, 0\right)+r\left(\rho_{n_{0}}-u\left(t_{0}\right)\right)\right] \\
& <0
\end{aligned}
$$

a contradiction.

Consequently (3.10) is true. Next we show

$$
u(t) \leq M \text { for } t \in[0,1] .
$$

Suppose (3.11) is false. Now since $u(0)=u(1)=\rho_{n_{0}}$ there exists either $(i) t_{1}, t_{2} \in$ $(0,1)$ with $\rho_{n_{0}} \leq u(t) \leq M$ for $t \in\left[0, t_{2}\right), u\left(t_{2}\right)=M$ and $u(t)>M$ on $\left(t_{2}, t_{1}\right)$ with 
$u^{\prime}\left(t_{1}\right)=0$; or $\left(\right.$ ii) $t_{3}, t_{4} \in(0,1), t_{4}<t_{3}$ with $\rho_{n_{0}} \leq u \leq M$ for $t \in\left(t_{3}, 1\right], u\left(t_{3}\right)=M$ and $u(t)>M$ on $\left(t_{4}, t_{3}\right)$ with $u^{\prime}\left(t_{4}\right)=0$.

We can assume without loss of generality that either $t_{1} \leq \frac{1}{2}$ or $t_{4} \geq \frac{1}{2}$. Suppose that $t_{1} \leq \frac{1}{2}$. Notice that for $t \in\left(t_{2}, t_{1}\right)$ we have

$$
\left(\varphi_{p}\left(u^{\prime}\right)\right)^{\prime}=f^{*}\left(t, u, u^{\prime}\right) \leq C q(t) h(M)(C \text { is defined in (3.6) }) .
$$

Integrate (3.12) from $t_{2}$ to $t_{1}$ to obtain

$$
\varphi_{p}\left(u^{\prime}\left(t_{2}\right)\right) \leq C h(M) \int_{t_{2}}^{t_{1}} q(s) d s
$$

and this together with the fact that $u\left(t_{2}\right)=M$ yields

$$
\varphi_{p}\left(u^{\prime}\left(t_{2}\right)\right) \leq C h(M) \int_{t_{2}}^{t_{1}} q(s) d s
$$

Also for $t \in\left(0, t_{2}\right)$ we have

$$
\begin{aligned}
-\left(\varphi_{p}\left(u^{\prime}\right)\right)^{\prime} & =f^{*}\left(t, u, u^{\prime}\right) \\
& \leq C q(t) h(u(t)) \\
& \leq C q(t) h(M)
\end{aligned}
$$

Integrate from $t\left(t \in\left(0, t_{2}\right)\right)$ to $t_{2}$ to obtain

$$
-\varphi_{p}\left(u^{\prime}\left(t_{2}\right)\right)+\varphi_{p}\left(u^{\prime}(t)\right) \leq C h(M) \int_{t}^{t_{2}} q(s) d s,
$$

so

$$
\varphi_{p}\left(u^{\prime}(t)\right) \leq C h(M) \int_{t}^{t_{2}} q(s) d s+\varphi_{p}\left(u^{\prime}\left(t_{2}\right)\right) .
$$

This together with (3.13) yields

$$
\varphi_{p}\left(u^{\prime}(t)\right) \leq C h(M) \int_{t}^{t_{1}} q(s) d s \text { for } t \in\left(0, t_{2}\right) .
$$

Thus

$$
u^{\prime}(t) \leq \varphi_{p}^{-1}(C h(M)) \varphi_{p}^{-1}\left(\int_{t}^{t_{1}} q(s) d s\right) \text { for } t \in\left(0, t_{2}\right) .
$$

Integrate from 0 to $t_{2}$ to obtain

$$
M-\rho_{n_{0}} \leq \varphi_{p}^{-1}(C h(M)) \int_{0}^{t_{2}} \varphi_{p}^{-1}\left(\int_{t}^{t_{1}} q(s) d s\right) .
$$

That is

$$
\begin{aligned}
M-\rho_{n_{0}} & \leq \varphi_{p}^{-1}(\operatorname{Ch}(M)) \int_{0}^{\frac{1}{2}} \varphi_{p}^{-1}\left(\int_{t}^{\frac{1}{2}} q_{\rho_{n_{0}}}(s) d s\right) d t \\
& \leq \varphi_{p}^{-1}(\operatorname{Ch}(M)) b_{0} .
\end{aligned}
$$

This contradicts (3.5) so (3.11) holds (a similar argument yields a contradiction if $\left.t_{4} \geq \frac{1}{2}\right)$. 
Thus we have

$$
\rho_{n_{0}} \leq u(t) \leq M \text { for } t \in[0,1]
$$

Next we show that

$$
\left|u^{\prime}\right|_{\infty}=\sup _{t \in[0,1]}\left|u^{\prime}(t)\right| \leq N .
$$

Suppose (3.14) is false. Without loss of generality assume $u^{\prime}(t) \not \leq N$ for some $t \in[0,1]$. Then since $u(0)=u(1)=\rho_{n_{0}}$ there exists $\tau_{1} \in(0,1)$ with $u^{\prime}\left(\tau_{1}\right)=0$, and so there exists $\tau_{2}, \tau_{3} \in(0,1)$ with $u^{\prime}\left(\tau_{3}\right)=0, u^{\prime}\left(\tau_{2}\right)=N$ and $0 \leq u^{\prime}(s) \leq N$ for $s$ between $\tau_{3}$ and $\tau_{2}$. Without loss of generality assume that $\tau_{3}<\tau_{2}$. Now since $\rho_{n_{0}} \leq u(t) \leq M$ for $t \in[0,1]$ and (with $\varepsilon=\rho_{n_{0}}$ )

$$
\left(\varphi_{p}\left(u^{\prime}\right)\right)^{\prime} \leq q(t) h(M) \Psi_{\varepsilon}\left(\varphi_{p}\left(u^{\prime}(t)\right)\right)
$$

and so

$$
\int_{0}^{\varphi_{p}(N)} \frac{d u}{\Psi_{\varepsilon}\left(\varphi_{p}^{-1}(u)\right)}=\int_{\tau_{3}}^{\tau_{2}} \frac{\left(\varphi_{p}\left(u^{\prime}\right)\right)^{\prime}}{\Psi_{\varepsilon}\left(u^{\prime}(s)\right)} d s \leq h(M) \int_{0}^{1} q(s) d s .
$$

This contradicts (3.4). The other cases are treated similarly. As a result $\rho_{n_{0}} \leq u(t) \leq M$ for $t \in[0,1]$ and $\left|u^{\prime}\right|_{\infty} \leq N$.

Let $\beta(t)=u(t)$ for $t \in[0,1]$. Then

$$
\left\{\begin{array}{l}
\left.\beta \in C^{1}[0,1], \quad\left(\varphi_{p} \beta^{\prime}\right)\right)^{\prime} \in C(0,1) \\
\text { with } \beta(t) \geq \rho_{n_{0}} \text { for } t \in[0,1] \text { and } \\
-\left(\varphi_{p}\left(\beta^{\prime}\right)\right)^{\prime}=f\left(t, \beta(t), \beta^{\prime}(t)\right) \text { for } t \in(0,1)
\end{array}\right.
$$

and

$$
-\left(\varphi_{p}\left(\beta^{\prime}\right)\right)^{\prime}=f\left(t, \beta(t), \beta^{\prime}(t)\right) \geq f\left(\frac{1}{2^{n_{0}+1}}, \beta(t), \beta^{\prime}(t)\right) \text { for } t \in\left(0, \frac{1}{2^{n_{0}+1}}\right) .
$$

As a result (2.4) and (2.5) are satisfied.

TheOREM 3.1. Suppose (2.1), (3.1) and (3.3) - (3.5), (3.7), (3.8) (here $b_{0}$ and $C$ are as in (3.6)) hold. Then problem (1.1) has a solution $u \in C[0,1] \cap C^{1}(0,1)$ with $\left(\varphi_{p}\left(u^{\prime}\right)\right)^{\prime} \in C(0,1)$.

\section{Examples.}

EXAMPLE 1. Consider the boundary value problem

$$
\left\{\begin{array}{l}
-u^{\prime \prime}=\frac{1}{\sqrt{t}}\left(\frac{1}{u^{2}}-1\right) h(u)\left(\left|u^{\prime}\right|+1\right), 0<t<1 \\
u(0)=u(1)=0
\end{array}\right.
$$

with

$$
h(u)=\left\{\begin{array}{l}
\frac{\sqrt{2} u}{40}+0.05 \text { for } 0 \leq u \leq \sqrt{2} \\
u^{2}-1.9 \text { for } \sqrt{2}<u .
\end{array}\right.
$$

Then (4.1) has a solution $u \in C[0,1] \cap C^{1}(0,1)$ with $\left(\varphi_{p}\left(u^{\prime}\right)\right)^{\prime} \in C(0,1)$. 
To see that (4.1) has a solution we will apply Theorem 3.1. Let $n \in\{1,2, \cdots\}$, $p=2$ and $\rho_{n}=\frac{1}{\sqrt{n+1}}$. Let $k_{0}=0.05$. Then, for $\frac{1}{2^{n+1}} \leq t \leq 1,0<u \leq \rho_{n}$ and $v \in R$ we have

$$
\begin{aligned}
f(t, u, v) & =\frac{1}{\sqrt{t}}\left(\frac{1}{u^{2}}-1\right) h(u)(|v|+1) \\
& \geq h(u)((n+1)-1) \geq 0.05=k_{0},
\end{aligned}
$$

so (3.1) is satisfied.

Let $n_{0}=1$ so $\rho_{n_{0}}=\frac{\sqrt{2}}{2}$, and let $M=\sqrt{2}$ and $N=10$. Let $q(t)=\frac{1}{\sqrt{t}}$ and $\Psi(v)=$ $|v|+1$. Then

$$
C=\max _{v \in[-N, N]} \Psi(v)=11, \int_{0}^{1} \frac{d t}{\sqrt{t}}=2, b_{0}=\int_{0}^{\frac{1}{2}} \int_{s}^{\frac{1}{2}} \frac{d t}{\sqrt{t}} d s=\frac{\sqrt{2}}{6},
$$

so

$$
|f(t, u, v)| \leq q(t) h(u) \Psi(|v|) \text { for }(t, u, v) \in(0,1] \times\left[\rho_{1}, \infty\right) \times R .
$$

Also notice that

$$
\begin{gathered}
h(M) \int_{0}^{1} q(t) d t=0.2, \\
\int_{0}^{N} \frac{d u}{\Psi(v)}=\ln 10 \cong 2.3026, \\
M-\rho_{1}=\sqrt{2}-\frac{\sqrt{2}}{2}=\frac{\sqrt{2}}{2}
\end{gathered}
$$

and

$$
C h(M) b_{0}=11 \times 0.1 \times \frac{\sqrt{2}}{6}=\frac{11 \sqrt{2}}{60} .
$$

As a result (3.3)-(3.5) are satisfied. We next establish (3.7).

Let $\Psi_{\varepsilon}(v)=\left(\frac{1}{\varepsilon^{2}}+1\right)(|v|+1)$. Then

$$
|f(t, u, v)| \leq q(t) \Psi_{\varepsilon}(|v|) \text { for }(t, u, v) \in(0,1) \times[\varepsilon, M] \times R .
$$

Also

$$
\begin{aligned}
\int_{0}^{K} \frac{d v}{\Psi_{\varepsilon}(v)} & =\frac{\varepsilon^{2}}{1+\varepsilon^{2}} \int_{0}^{K} \frac{d v}{v+1} \\
& \geq \frac{\varepsilon^{2}}{1+\varepsilon^{2}} \ln (K+1) \rightarrow \infty(\text { as } K \rightarrow \infty)
\end{aligned}
$$

i.e.

$$
\int_{0}^{\infty} \frac{d v}{\Psi_{\varepsilon}\left(\varphi_{p}^{-1}(v)\right)}=\infty
$$

and

$$
\int_{0}^{1} \frac{d t}{\sqrt{t}}=2
$$


Then

$$
\int_{0}^{1} q(s) d s<\infty \text { and } \int_{0}^{1} q(s) d s<\int_{0}^{\infty} \frac{d u}{\Psi_{\varepsilon}\left(\varphi_{p}^{-1}(u)\right)}
$$

so (3.7) holds. Finally $f(t, u, v)$ is nonincreasing on $\left(0, \frac{1}{4}\right)$ for each fixed $(u, v) \in$ $\left[\rho_{n_{0}}, M\right] \times[-N, N]$, so (3.8) is satisfied. Theorem 3.1 guarantees that (4.1) has a solution $u \in C[0,1] \cap C^{1}(0,1)$ with $\left(\varphi_{p}\left(u^{\prime}\right)\right)^{\prime} \in C(0,1)$.

EXAMPLE 2. Consider the boundary value problem

$$
\left\{\begin{array}{l}
-\left(\left|u^{\prime}\right|^{p-2} u^{\prime}\right)^{\prime}=\frac{1}{\sqrt{t} u^{\alpha}}+\left|u^{\prime}\right|^{\beta}-r(t), 0<t<1 \\
u(0)=u(1)=0
\end{array}\right.
$$

with $p>1, \alpha>0, r \in C[0,1]$ and $\beta>0$ is such that

$$
\int_{0}^{\infty} \frac{d v}{\left(v^{\frac{1}{p-1}}+1\right)^{\beta}}=\infty
$$

Then (4.2) has a solution $u \in C[0,1] \cap C^{1}(0,1)$.

Let $n \in\{1,2, \cdots\}$ and $\rho_{n}=\frac{1}{n\left(1+C_{1}\right)^{1 / \alpha}}$ where $C_{1}=\max _{t \in[0,1]}|r(t)|$. Also let $k_{0}=1$, so for $\frac{1}{2^{n+1}} \leq t \leq 1,0<u \leq \rho_{n}$ and $v \in R$ we have

$$
\begin{aligned}
f(t, u, v) & =\frac{1}{\sqrt{t} u^{\alpha}}+|v|^{\beta}-r(t) \\
& \geq \frac{1}{\sqrt{t} u^{\alpha}}-C_{1} \\
& \geq \frac{1}{u^{\alpha}}-C_{1} \geq 1=k_{0}
\end{aligned}
$$

and so (3.1) holds. Next let

$$
\begin{aligned}
& h(u)=1+\frac{1}{\rho_{1}^{\alpha}}+C_{1}, q(t)=\frac{1}{\sqrt{t}} \\
& \text { and } \Psi(v)=(v+1)^{\beta} \text { for } v \in[0, \infty) .
\end{aligned}
$$

For $(t, u, v) \in(0,1] \times\left[\rho_{1}, \infty\right) \times R$, we have

$$
\begin{aligned}
|f(t, u, v)| & \leq \frac{1}{\sqrt{t} \rho_{1}^{\alpha}}+C_{1}+\Psi(|v|) \\
& \leq \frac{1}{\sqrt{t}}\left[\frac{1}{\rho_{1}^{\alpha}}+C_{1}+\Psi(|v|)\right] \\
& \leq \frac{1}{\sqrt{t}}\left(1+\frac{1}{\rho_{1}^{\alpha}}+C_{1}\right) \Psi(|v|) .
\end{aligned}
$$

Let $N>0$ be such that

$$
\int_{0}^{\varphi_{p}(N)} \frac{d v}{\left(v^{\frac{1}{p-1}}+1\right)^{\beta}}>2\left(1+\frac{1}{\rho_{1}^{\alpha}}+C_{1}\right)
$$


and $M>0$ be such that

$$
M>\rho_{1}+b_{0}(N+1)^{\frac{\beta}{p-1}}\left(1+\frac{1}{\rho_{1}^{\alpha}}+C_{1}\right)^{\frac{1}{p-1}}
$$

where

$$
b_{0}=\max \left\{\int_{0}^{\frac{1}{2}}(\sqrt{2}-2 \sqrt{s})^{\frac{1}{p-1}} d s, \int_{\frac{1}{2}}^{1}(2 \sqrt{s}-\sqrt{2})^{\frac{1}{p-1}} d s\right\}
$$

Then (3.3)-(3.5) are satisfied. We next establish (3.7).

For any $\varepsilon>0$, let

$$
\Psi_{\varepsilon}(v)=\left(1+\frac{1}{\varepsilon^{\alpha}}+C_{1}\right)(v+1)^{\beta} \text { for } v \in[0, \infty) .
$$

Now for $(t, u, v) \in(0,1] \times[\varepsilon, M] \times R$, we have,

$$
\begin{aligned}
|f(t, u, v)| & \leq \frac{1}{\sqrt{t} \varepsilon^{\alpha}}+C_{1}+(|v|+1)^{\beta} \\
& \leq \frac{1}{\sqrt{t}}\left(\frac{1}{\varepsilon^{\alpha}}+C_{1}+(|v|+1)^{\beta}\right) \\
& \leq q(t)\left(1+\frac{1}{\varepsilon^{\alpha}}+C_{1}\right)(|v|+1)^{\beta} \\
& =q(t) \Psi_{\varepsilon}(|v|) .
\end{aligned}
$$

Also

$$
\int_{0}^{K} \frac{d v}{\Psi_{\varepsilon}\left(\varphi_{p}^{-1}(v)\right)}=\frac{\varepsilon^{\alpha}}{1+\left(1+C_{1}\right) \varepsilon^{\alpha}} \int_{0}^{K} \frac{d v}{\left(v^{\frac{1}{p-1}}+1\right)^{\beta}} \rightarrow \infty(\text { as } K \rightarrow \infty)
$$

so

$$
\int_{0}^{\infty} \frac{d v}{\Psi_{\varepsilon}\left(\varphi_{p}^{-1}(v)\right)}=\infty
$$

As a result

$$
\int_{0}^{1} q(s) d s<\infty \text { and } \int_{0}^{1} q(s) d s<\int_{0}^{\infty} \frac{d u}{\Psi_{\varepsilon}\left(\varphi_{p}^{-1}(u)\right)},
$$

so (3.7) holds. Finally $f(t, u, v)$ is nonincreasing on $\left(0, \frac{1}{4}\right)$ for each fixed $(u, v) \in$ $\left[\rho_{1}, M\right] \times[-N, N]$, so (3.8) is satisfied. Theorem 3.1 guarantees that (4.2) has a solution $u \in C[0,1] \cap C^{1}(0,1)$ with $\left(\varphi_{p}\left(u^{\prime}\right)\right)^{\prime} \in C(0,1)$.

\section{REFERENCES}

1. R. Agarwal, H. Lü and D. O'Regan, Existence theorems for the one-dimensional singular $p$-Laplacian equation with sign changing nonlinearities, Appl. Math. Comp. 143 (2003), 15-38.

2. R. Agarwal, D. O'Regan and R. Precup, Construction of upper and lower solutions with applications to singular boundary value problems, J. Computational Analysis and Applications, to appear. 
3. P. Habets and F. Zanolin, Upper and lower solutions for a generalized Emden-Fowler equation, J. Math. Anal. Appl. 181 (1994), 684-700.

4. D. D. Hai and R. Shivaji, An existence result for a class of superlinear $p$-Laplacian semipositone systems, Diff. Int. Equ. 14 (2001), 231-240.

5. H. Lü, D. O'Regan and C. Zhong, Existence of positive solutions for the singular equation $\left(\phi_{p}\left(y^{\prime}\right)\right)^{\prime}+g\left(t, y, y^{\prime}\right)=0$, Nonlinear Oscillations 6 (2003), 117-132.

6. $\mathrm{H}$. Lü and C. Zhong, A note on singular nonlinear boundary value problems for the one-dimensional p-Laplacian, Appl. Math. Letters 14 (2001), 189-194.

7. H. Lü, D. O'Regan and C. Zhong, Multiple positive solutions for the one-dimensional singular $p$-Laplacian, Appl. Math. Comp. 133 (2002), 407-722.

8. R. F. Manásevich and F. Zanolin, Time-mapping and multiplicity of solutions for the one-dimensional p-Laplacian, Nonlinear Analysis 21 (1993), 269-291.

9. D. O'Regan, Some general existence principle and results for $\left(\phi\left(y^{\prime}\right)\right)^{\prime}=q f\left(t, y, y^{\prime}\right)$, $0<t<1$, SIAM J. Math. Anal. 24 (1993), 648-668.

10. J. Wang and W. Gao, A singular boundary value problem for the one-dimensional p-Laplacian, J. Math. Anal. Appl. 201 (1996), 851-866.

11. Q. Yao and H. Lü, Positive solutions of one-dimensional singular $p$-Laplace equations, Acta Mathematica Sinica, 41(6), (1998), 1253-1264.

12. P. Drábek, On the Fredholm alternative for nonlinear homogeneous operators, Applied Nonlinear Analysis, (Kluwer Academic/Plenum Publishers, New York, 1999), 41-48. 